\title{
POST-DISASTER ASSESSMENT OF MANGROVE FOREST RECOVERY IN LAWAAN-BALANGIGA, EASTERN SAMAR USING NDVI TIME SERIES ANALYSIS
}

\author{
K. E. Cabello ${ }^{1 *}$, M.Q. Germentil ${ }^{1}$, A.C. Blanco ${ }^{12}$, E.G. Macatulad ${ }^{12}$, S.G. Salmo III ${ }^{3}$ \\ ${ }^{1}$ Department of Geodetic Engineering, College of Engineering, University of the Philippines Diliman - kecabello@up.edu.ph*, \\ mqgermentil@up.edu.ph, ${ }^{2}$ Training Center for Applied Geodesy and Photogrammetry, University of the Philippines Diliman - \\ acblanco@up.edu.ph, egmacatulad@up.edu.ph, ${ }^{3}$ Institute of Biology, College of Science, University of the Philippines Diliman - \\ sgsalmo@gmail.com
}

KEY WORDS: mangroves, Landsat 8, Sentinel 2, NDVI, LAI, time series analysis, post-disaster assessment, GEE

\begin{abstract}
:
In 2013, Typhoon Haiyan (Yolanda) struck the Eastern Philippines. Mangrove forests in the area were destroyed and were estimated to have at least $86 \%$ of damage. Some studies done on the typhoon-stricken mangroves had collected data such as measurements of mangrove trunk, height, roots, and seedlings to investigate the extent of damage and recovery. While these studies were proven to effectively identify mangrove gains and losses, these methods are only applicable in sites that are relatively accessible. This paper highlights the relevance of effective remote monitoring of mangrove forests that are vulnerable to typhoons including post-typhoon recovery. In this study, a Time Series Analysis using Google Earth Engine (GEE) was applied in assessing the damages and recovery of mangroves struck by Super Typhoon Haiyan in Lawaan and Balangiga, Samar (Eastern Philippines). The changes in mangrove extent followed the changes in NDVI; however, there were significant site-specific differences. Based on NDVI values, it was estimated that $83 \%$ of the mangrove area was damaged. After three years, regeneration from 2014-2017 was about 144\%. Mangroves steadily developed but with a minimal change of $2.83 \%$ from 2017-2019. Most villages followed the general recovery trends in Lawaan and Balangiga. However, based on the time series analysis, some villages have minimal recovery than others. It suggests that the recovery of mangroves may be a function of the pre-typhoon mangrove extent and possibly vegetation condition. Even if there were new spaces for mangroves to colonize, some of the sites may not be conducive for plant regrowth.
\end{abstract}

\section{INTRODUCTION}

Mangrove forests are among the world's most productive ecosystems. They often grow in tropical and subtropical latitudes where they thrive in regions with high salinity, high temperatures, extreme tides, and strong winds. (Bingham et al., 2001) Though exposed to such extremes, mangroves have developed several unique adaptations such as lateral roots (for anchoring in loose sediments), exposure of aerial roots (for gas exchange) (Bingham et al., 2001), and salt exclusion at the root level. (Perri et al., 2016)

The Philippines is one of the top mangrove biodiversity "hotspots" in the world with at least 35 mangrove species. (Long \& Giri, 2011) But since the country is so typhoon-prone (Vergano, 2013), it continues to suffer mangrove losses. For the past decade, the country has already experienced two typhoons, one of which is Super Typhoon Haiyan (Yolanda) in 2013 (PanahonTV, 2017). It is one of the most catastrophic typhoons that struck the country and nearly wiped-out the mangrove areas in the central Visayas region.

Some post-typhoon mangrove studies were conducted in Eastern Samar and Palawan which were two provinces highly affected by Typhoon Haiyan in 2013. One study by Alura et al. (2016) focused on thriving mangrove species post-typhoon for implementation of rehabilitation technique and damage \& recovery assessments conducted on Calauit Island, Palawan (Malabrigo et al., 2016) and Coron, Palawan \& Balangiga-Lawaan (Buitre et al., 2019)

This research analyzed the mangrove forests of Balangiga-Lawaan and assessed the damage due to Typhoon Haiyan in 2013 and the subsequent recovery from 2014-2019 using Sentinel-2 and Landsat imageries. These were carried out by creating a Time Series Analysis and Ordinary Least Squares (OLS) Regression estimates of the slope of Normalized Difference Vegetation Index (NDVI) and Leaf Area Index (LAI).

Landsat-8 OLI/TIRS images in the Google Earth Engine (GEE) scripts were used for the initial damage and recovery assessment. Sentinel $2 \mathrm{~A}$ and 2B derivative datasets (i.e., NDVI, LAI) were also used and assessed using Excel and SPSS (Statistical Packaging for the Social Sciences) to understand the changes in the mangrove areas. The researchers encountered some constraints during the implementation of this study due to the ongoing COVID-19 pandemic (e.g., limited access to ground data collection). The entire study was limited to datasets derived from GEE and other online resources. Small deviations in the values from the computations may be attributed to the errors brought by the calibration of the satellite images.

\section{REVIEW OF RELATED LITERATURE}

\subsection{Mangrove Forests \& Typhoon Haiyan}

The typhoon Haiyan (Yolanda) has had six (6) landfalls affecting the areas of Samar, Leyte, Cebu, Iloilo, and Palawan (Mangosing, 2013). The extent of the destruction was assessed and measured in some sites. Published studies have been recorded like Salmo's and Gianan's (2019) study on the mangroves of Salcedo, Samar with regards to the post-typhoon carbon stocks. Strong catastrophic typhoons like Haiyan are known to result in the uprooting of trees, breaking off branches, defoliation, and massive mortality leads to severe reductions in total carbon stock (TCS) of the area.

* corresponding author 
A damage assessment on the mangroves of Calauit Island, Palawan was conducted by Malabrigo, et al. (2016) from ten $10 \mathrm{~m} \times 10 \mathrm{~m}$ sampling quadrats. All quadrants were evaluated and assigned to a specific damage status ranging from none to severely damaged. Study shows that the Calauit mangroves suffered damages with $20 \%$ of the plots having $100 \%$ mortality. Only $21 \%$ of the recorded trees were intact and presumed to be $100 \%$ recovered in shoot development.

A few species-specific studies were conducted like the study of Carlos et. al (2015) in Tacloban and Ormoc, Leyte. The research assessed three mangrove genera - Rhizophora, Sonneratia, and Avicennia. Each corresponding genus' vegetation resistance (VR), and seedling regeneration potential (SPR) were assessed to know which of the three is the most resilient. Their results showed that both Sonneratia and Avicennia have higher natural regeneration rates due to success in seedling recruitment.

\subsection{Normalized Difference Vegetation Index (NDVI)}

Normalized Difference Vegetation Index (NDVI) is a vegetation index measured by getting the ratio between the difference and sum of Near Infrared (NIR) and Red channels of image.

$$
N D V I=\frac{N I R-R E D}{N I R+R E D}
$$

NDVI is used in agriculture, forestry, and environmental studies as a standard parameter for the identification of photosynthetically active or healthy vegetation. This ratio ranges from -1 (no vegetation) to +1 (healthy vegetation). Values close to the negative spectrum correspond to areas of water, built-up, and other man-made structures. Bare soil ranges from 0.1 to 0.2 . Grasslands/sparse vegetation have NDVI values from 0.2 to 0.5 , and dense vegetation has values above 0.5. (EOS.com, 2019)

In recent studies, NDVI was used to explore impacts of climate variability on mangrove ecosystems (Flores-Cárdenas et al., 2018) and even as a parameter for estimating mangrove health index (Akbar et al., 2020). One example of its reliability in mangrove mapping was a developed index called CMRI (Combined Mangrove Recognition Index) which is a combination of NDVI and Normalized Difference Water Index (NDWI) used to discriminate mangroves from non-mangroves in India. This index was tested for three (3) mangrove sites and had an average overall classification accuracy of $73 \%$. (Gupta et al., 2018)

\section{$2.3 \quad$ Leaf Area Index (LAI)}

Leaf Area Index (LAI) is a biophysical parameter that refers to the number of square meters of leaves present in one square meter of ground. For most crops, LAI can range from 5 to 7 $\left(\mathrm{m}^{2} / \mathrm{m}^{2}\right)$. Values from 3 to 4 usually refer to close canopy . (Airbus, 2020) Presence of leaves becomes an important indicator of radiation, precipitation interception, energy conversion, water balance, and a reliable parameter for plant growth. That is why most studies in precision agriculture and climate change use LAI as leaves are the most eco-physiological parts of the plant that interact with the atmosphere. (Trimble, 2019)

\subsection{Mangrove Vegetation Index}

A mangrove index was recently developed for rapid and accurate mangrove mapping specifically applied in the mangroves of the Philippines. Baloloy, et al. (2020) developed an equation that can delineate mangroves using NIR, SWIR, and green reflectance bands without the need for complex classification techniques which can be time-consuming and very user-skill-biased.

$$
M V I=\frac{\text { NIR-GREEN }}{\text { SWIR-GREEN }}
$$

The index is apt for the study area since it was designed by analyzing the spectral signatures and characteristics of mangroves and non-mangrove datasets from different sites in the Philippines and Japan. Accuracy assessments indicate that MVI on the average provides around 92\% accuracy. Its threshold values were then computed through the use of a nationwide field-acquired mangrove inventory and drone data. According to Baloloy, et al. (2020), the optimal minimum threshold values that can discriminate mangroves from non-mangroves areas were about 4.5 and 4.6, respectively with mean MVI varying depending on the type of mangrove forest. The mean MVI threshold value was 6.7 for riverine mangrove forests (forests found in rivers) and 8.9 for fringe mangrove types (forests found in coastal areas).

\section{DATA AND METHODS}

\section{1}

\section{Study Areas}

The municipalities of Lawaan and Balangiga are situated in Eastern Samar within the bounding coordinates Latitude: $11^{\circ} 19^{\prime}$ $0.62^{\prime \prime} \mathrm{N}$ to $11^{\circ} 4^{\prime} 54.95^{\prime \prime} \mathrm{N}$ and Longitude: $125^{\circ} 14^{\prime} 52.45^{\prime \prime} \mathrm{E}$ to $125^{\circ} 26^{\prime} 20.63^{\prime \prime}$ E (Figure 1). Both areas have villages near the Philippine Sea (East) and the Leyte Gulf (South). The mangrove areas studied were located on the coastal fringes of Bolusao, Guinoban, Beta-og, Poblacion I,II,II, Taguite, Maslog in Lawaan, and San Miguel, Poblacion V, Cansumangcay, Bacjao in Balangiga. 

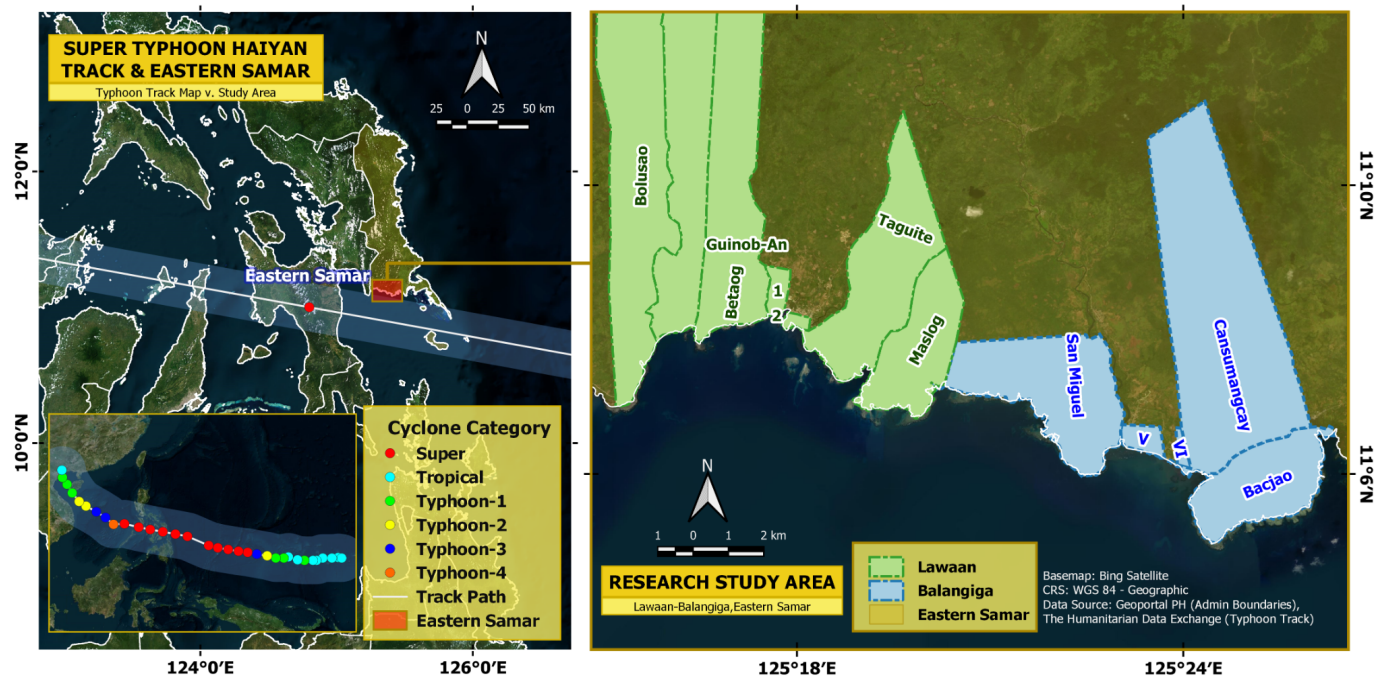

Figure 1. Map showing the track of typhoon Haiyan (left), and Lawaan-Balangiga, Samar and its coastal barangays

3.2 Time series analysis using Google Earth Engine and LAI processing ESA-SNAP

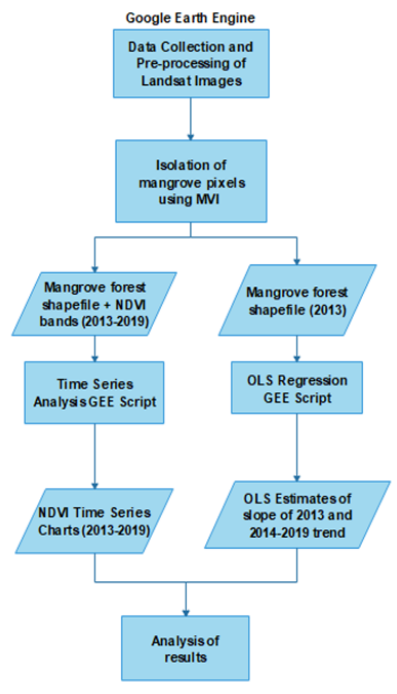

Figure 2. Flowchart for the NDVI Time Series and Ordinary Least Squares Regression

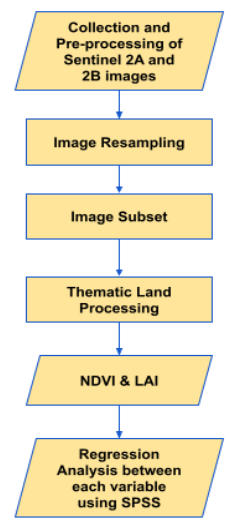

Figure 3. Flowchart for the ESA-SNAP Sentinel-2 image processing and Biophysical Parameter derivation

\subsubsection{Mangrove Forest Pixels}

Normalized Difference Vegetation Index (NDVI) and a newly developed mangrove vegetation index (MVI) (Baloloy, et al. 2020) were added to the list of spectral bands present on Landsat 8 images of the study area. NDVI and MVI were calculated using the red, green, SWIR, and NIR bands. The equations are as follows:

$$
\begin{aligned}
& \text { Landsat 8: } \mathrm{NDVI}=\frac{B 5-B 4}{B 5+B 4} \\
& \text { Landsat 8: } \mathrm{MVI}=\frac{B 5-B 3}{B 6-B 3}
\end{aligned}
$$

A mangrove mask function was created to separate the mangrove from the non-mangrove area. Using MVI bands per image, the range of values was set to 4.5 , the optimal minimum threshold (Baloloy, et al., 2020) up to a maximum of 20. Pixels within this range are mangrove areas.

\subsubsection{Time Series Analysis of the mangrove area}

Time series of the NDVI values of the mangroves in Lawaan and Balangiga, Eastern Samar was made. The time series shows the general trend of the mangrove growth in the area. The decline of NDVI indicates the loss and the increase indicates the gain or recovery. For each month from January 2013 to December 2019, the mean NDVI of the mangroves was transferred to a new image collection to create the general time-series graph. Time series analysis was also performed in each village to compare the trends of mangrove recovery.

\subsubsection{Ordinary Least Squares Regression Analysis}

Google Earth Engine's Ordinary Least Squares Regression (OLS) was used to estimate the slopes of the growth trend of mangroves each year. The slope indicates the rate of change of mangrove growth or loss in the study area. The output shapefile containing the mangrove extent of Lawaan and Balangiga in the year 2013 was used as the area of interest (AOI) for the regression analysis. The output of the OLS Regression script was used to confirm the rate at which the mangrove areas change over time. 


\subsubsection{Sentinel Data Collection and Processing}

Sentinel $2 \mathrm{~A}$ and $2 \mathrm{~B}$ satellite images were downloaded from EarthExplorer (https://earthexplorer.usgs.gov/) and prepared using the ESA-SNAP. The images were adjusted and fine-tuned using the Sen2Cor plugin of ESA-SNAP. This calibrates the satellite images and creates cloud masks. Sentinel 2A and 2B images have different spatial resolution per bands, therefore the images were resampled to 10 meters and then were subset to the study area.

\subsubsection{Thematic Land Processing}

Thematic Land Processing was done to compute the NDVI values of each image per month. The outputs of this processor were biophysical parameters used to assess the mangrove growth further. Leaf area index (LAI) was mainly used in this study. The researchers used LAI values greater than 3.0 to indicate mangroves that have reached closed canopy.

\section{RESULTS AND DISCUSSIONS}

4.1 NDVI time series analysis in Lawaan-Balangiga mangrove area

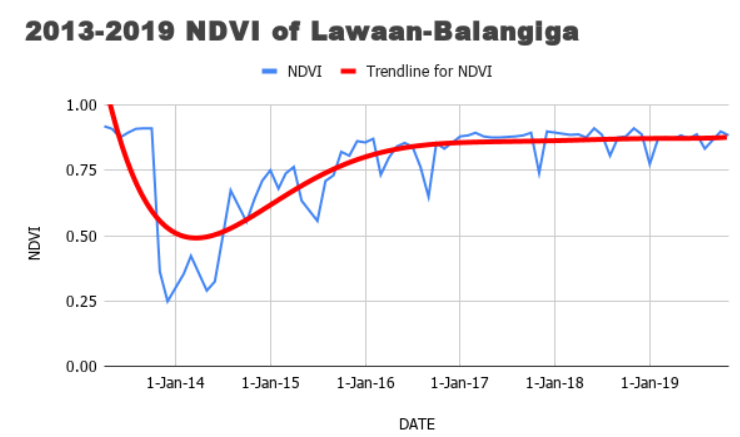

Figure 4. NDVI Time series chart of Lawaan - Balangiga mangroves

Based on the resulting time series chart (Figure 4), there has been a significant drop in NDVI immediately after Typhoon Haiyan. Values gradually increased starting in 2014 until they plateaued by 2017 indicating post-typhoon vegetation recovery (Figure 5). The general NDVI time series charts of the mangrove areas in Lawaan-Balangiga were divided into three different sections, namely (a) Damage Period, (b) Recovering Period, and (c) Stabilizing Period.

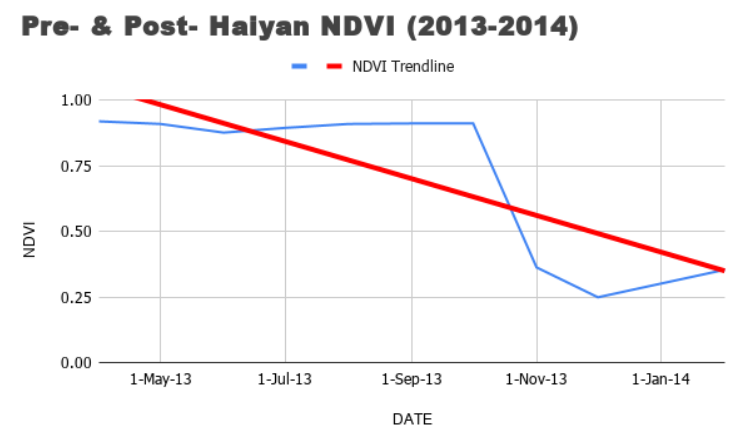

Figure 5. 2013 to Early 2014 NDVI Time Series Chart (Damaged Period)

The Damaged Period is from 2013-2014 in which the mean NDVI values dropped from October (pre-typhoon) and November 2013. The slope of the red trend line in the figure has a value of -17.48 . The absolute value of the slope describes the sudden drop of the NDVI value. The NDVI value drop is indicative of the significant mangrove loss in the area, estimated to be around $83.07 \%$. Around January 2014, the NDVI values started to increase. (Figure 5)

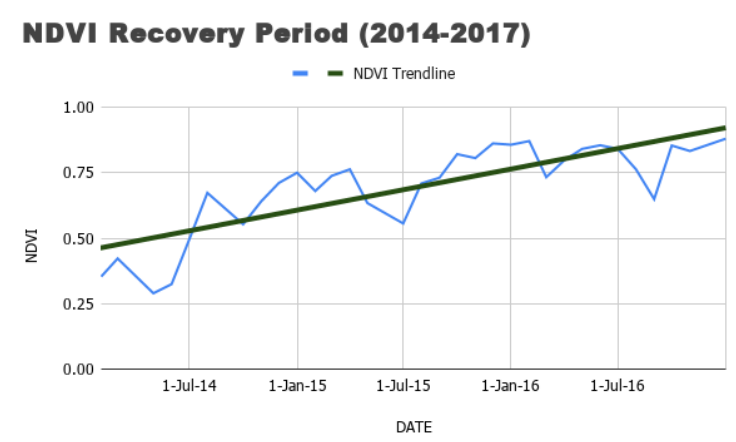

Figure 6. 2014 to Early 2017 NDVI Time Series Chart (Recovering Period)

The trend of the Recovering Period from 2014 to early 2017 has a value of 1.34. Mangrove area change was observed to be $114.30 \%$. Compared to the absolute slope of the Damaged Period, this has a smaller value indicating the rapid and steady growth of mangroves. (Figure 6)

\section{NDVI Stabllizing Perlod (2017-2019)}

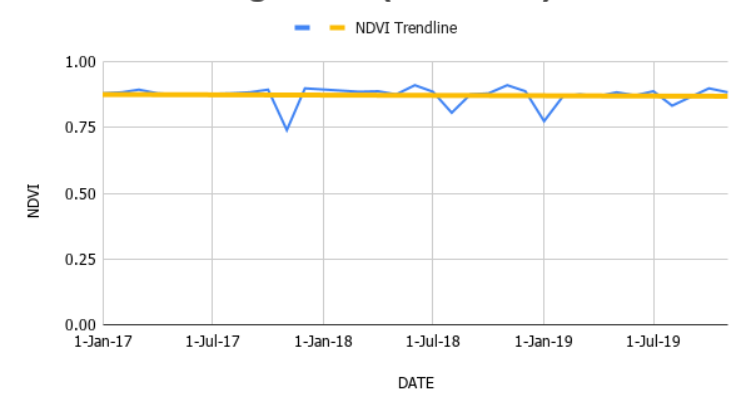

Figure 7. 2017-2019 NDVI Time Series Chart (Stabilizing Period)

The Stabilizing Period from 2017-2019 has a slope value of 0.093. During this period, the mangroves steadily grew with a mangrove change of $2.83 \%$. The mean NDVI values of the mangroves during this period stabilized and stayed around 0.8 . This shows that mangroves steadily recovered and most of it were retained up to 2019 (Figure 7).

The trends of NDVI per village followed the general growth patterns (Figures 8-9). This means that the general trend of mangrove growth shown in Figure 4 represents the mangrove growth in most villages. The villages of Taguite, Maslog, and San Miguel, not only have the largest mangrove cover in these two municipalities, but they also have closely similar trends during mid-2014. The NDVI started to exhibit signs of positive change in mangrove growth, although they had the greatest mangrove losses. 

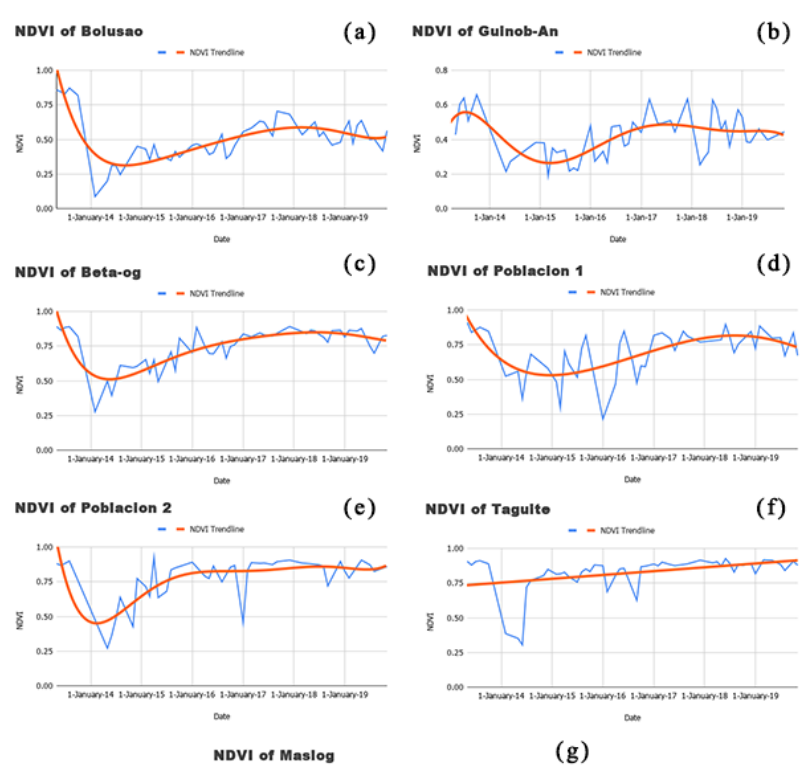

(g) (b)

(d)

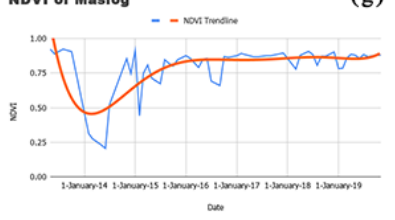

Figure 8. NDVI time series charts showing the general trend of mangrove growth for each coastal barangay of Lawaan (a)

Bolusao, (b) Guinob-an, (c) Beta-og, (d) Poblacion I, (e)

Poblacion II, (f) Taguite, (g) Maslog
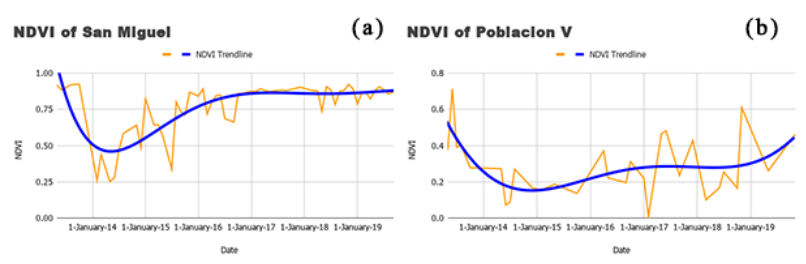

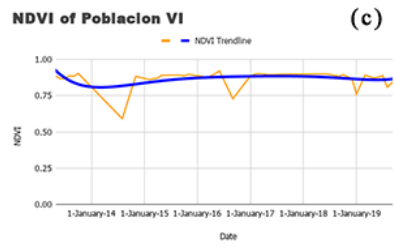

NDVI of Cansumangcay

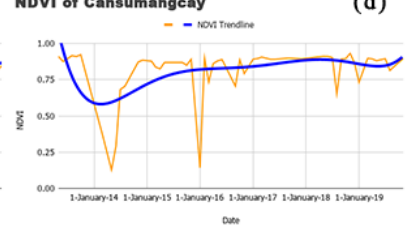

(e)

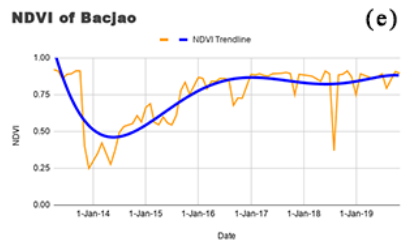

Figure 9. NDVI time series charts for each coastal barangay of Balangiga (a) San Miguel, (b) Poblacion V, (c) Poblacion VI, (d) Cansumangcay, (e) Bacjao
In contrast, smaller villages like Poblacion V and VI don't follow the trends of larger villages. Poblacion V NDVI values stayed around 0.75 while Poblacion VI deviated from 0.2 to 0.4 level. Some mangroves in Poblacion VI were not able to adapt and recover based on its NDVI time-series graph. The growth may be a function of the area. Even though there were new sites for mangrove to colonize, some mangroves were not able to recover.

\subsection{Ordinary Least Square (OLS) Slope Estimates for Growth Trend}

The OLS slope estimates were also able to quantify the rate of area change in the mangrove forests of Lawaan and Balangiga. Figures 10-11 shows that in the municipalities of Lawaan-Balangiga, the rates of change of the NDVI values varied depending on their location (if the barangay is more eastward) and the extent of the mangrove area (how large/small the villages are). The villages of San Miguel, Taguite, and Maslog were the three areas with the highest decline in the growth trend slope, which means that these areas had greater damage compared to other villages (Figures 8-9). It is evident that these areas had more mangrove losses mainly because they have vast mangrove forest than other villages.

\section{SLOPE OF GROWTH TREND IN LAWAAN}

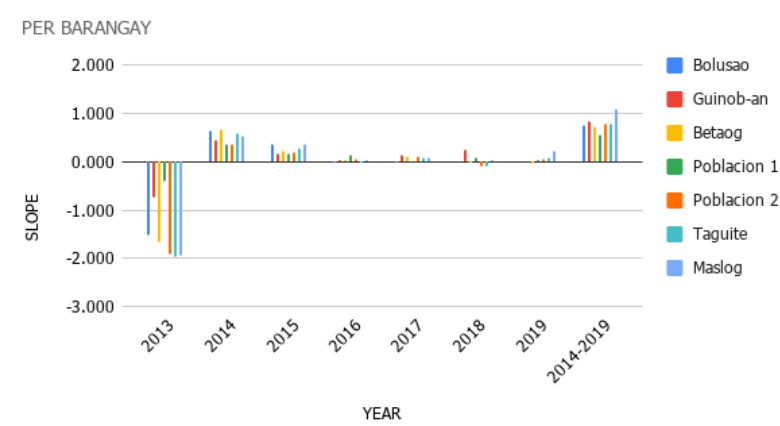

Figure 10. Bar graph showing the comparison of slopes per barangay in Lawaan

\section{SLOPE OF GROWTH TREND IN BALANGIGA}

PER BARANGAY

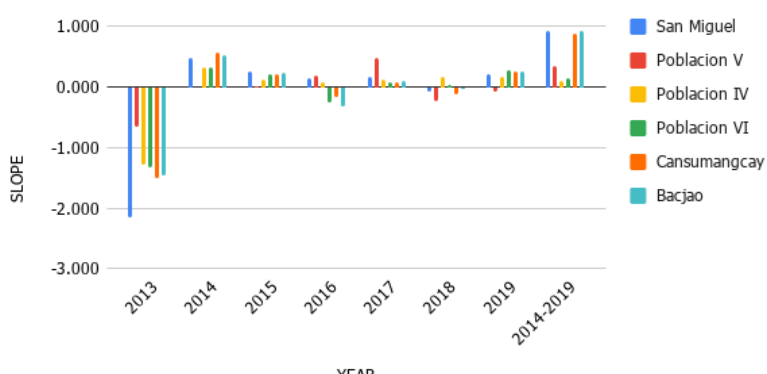

YEAR

Figure 11. Bar graph showing the comparison of slopes per barangay in Balangiga 


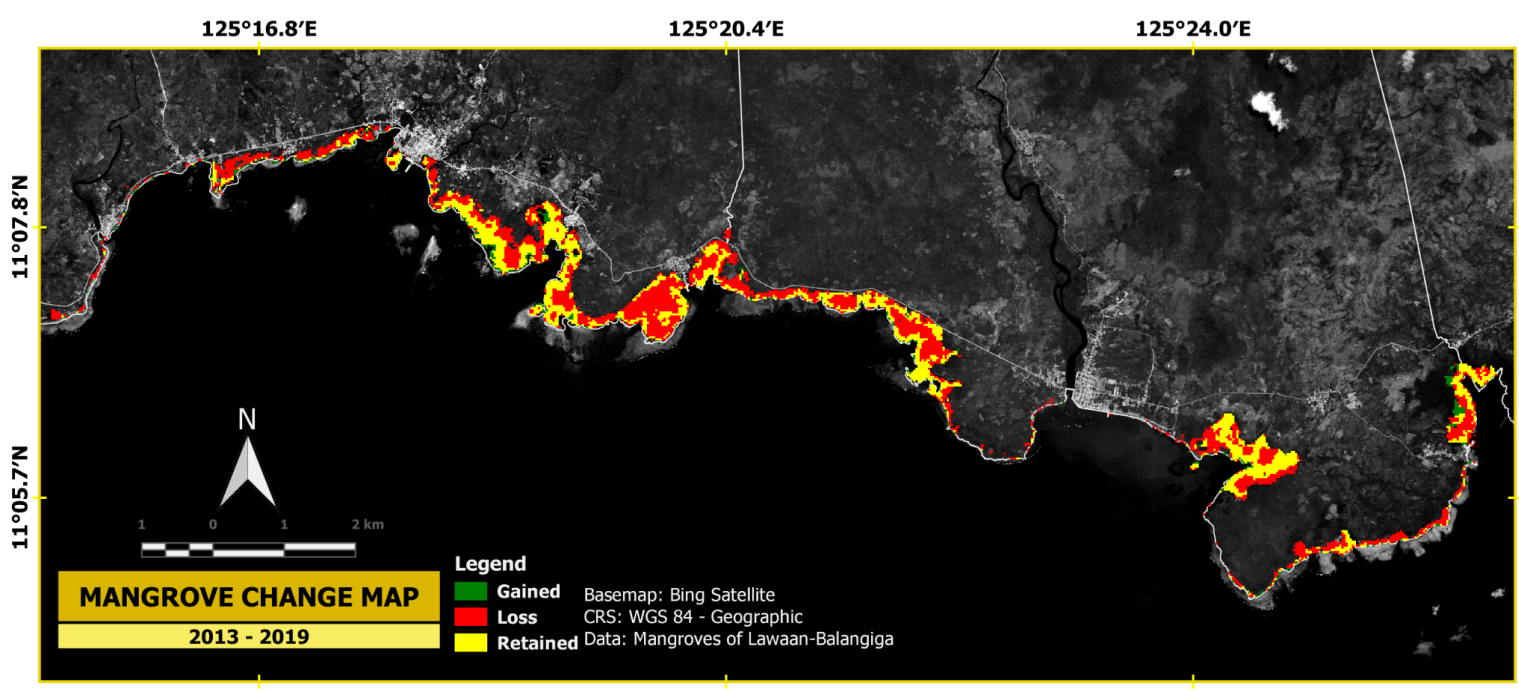

Figure 12. 2013-2019 Mangrove Area Change Map

Annual and 2013-2019 mangrove area change maps (see Figure 12) were created using MVI and NDVI in QGIS. NDVI values and MVI-detected mangrove pixels were used as inputs for the maps. These maps show the immensity of the mangrove loss vs. the changes that happened (i.e., recovery, retention) post-Haiyan. "Lost" areas (red) show mangrove forests decimated by Typhoon Haiyan (approximately 494.85 has) and additional mangrove areas lost thereafter until 2019 (around 54.86 has). "Retained" areas (yellow; estimated at 217.93 has) are mangroves which remained after Haiyan until 2019. As shown in Figure 12, there are minimal "gained" areas (green; ca. 23.35 hectares).

Between 2013 and 2019, the initial mangrove areas from the start of the analysis have grown back based on the areas tagged as gained (green) and retained (yellow) in the change map (Figure 13). Though there has been a recovery period from 2014-2017 which then stabilized until 2019, loss in the mangrove area in the study region is still evident. Not only in the 2013 vs. 2019 change map was this observed but also, mangrove areas that seemed to survive the typhoon as seen on the 2013-2014 change maps, eventually died in the succeeding years. Furthermore, continuous degradation in mangrove plants in some regions of the study area are still visible which can be seen in Figure 13 even though rehabilitation efforts were conducted.

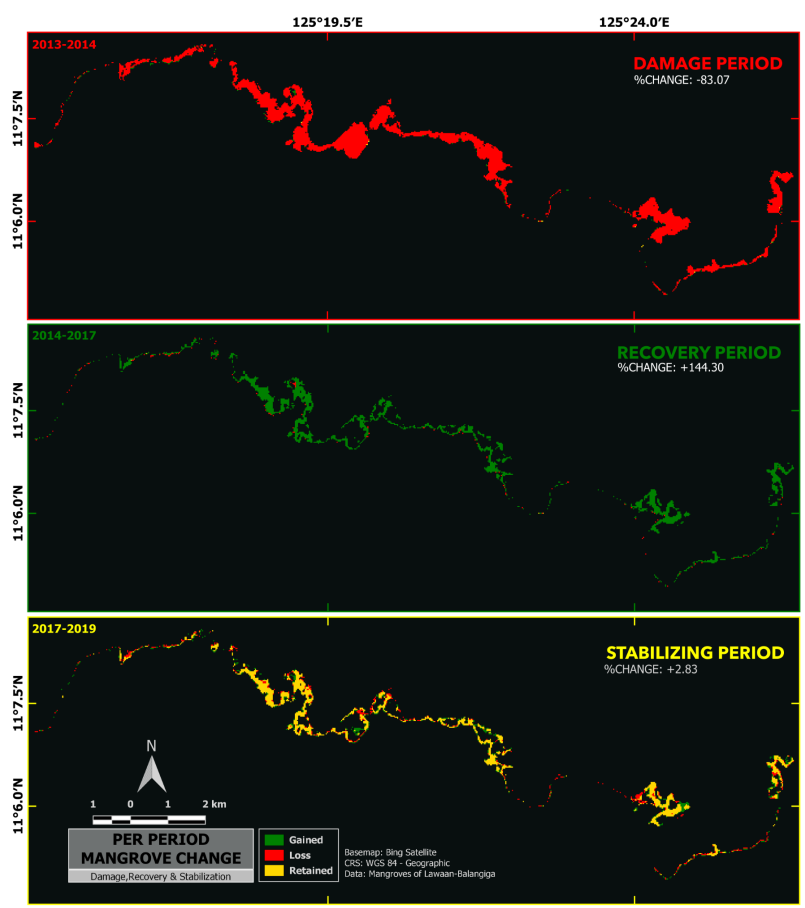

Figure 13. Damaged Period (2013-2014), Recovery Period (2014-2017) \& Stabilizing Period (2017-2019) Mangrove Change Maps 
Mangrove canopy area maps were produced. These show mangrove areas with NDVI values $0.6-1.0$ and LAI values 3.0-4.0, referring to healthy mangroves that have reached closed canopy. These areas generally increased from 606.2 ha in April 2017 (Figure 14a) to 1047.3 ha in June 2019 (Figure 14b). This positive change in area based on NDVI and LAI confirms that the mangroves in Lawaan and Balangiga continued to grow from 2017 to 2019 .

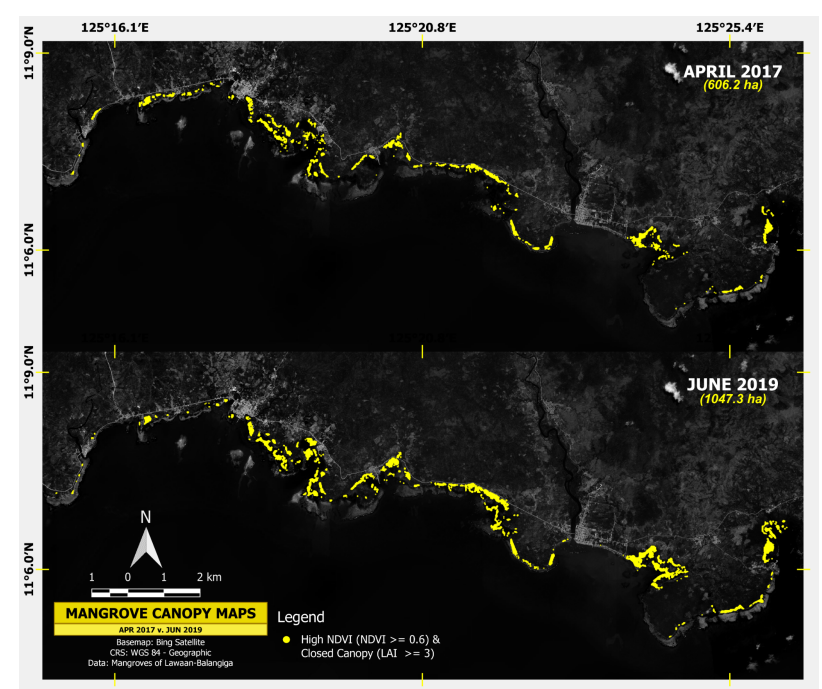

Figure 14. Mangrove canopy area maps (a) APRIL 2017 (b) JUNE 2019

\section{CONCLUSIONS}

This research was intended to investigate the (a) mangrove damage brought by Typhoon Haiyan to Lawaan-Balangiga, Eastern Samar in November 2013, and the (b) mangrove growth and recovery six years post-disaster from 2014 to 2019. The study documented general rapid mangrove recovery but stabilized 4-5 years post-typhoon Haiyan. However, the recurrence of mangrove losses from the initial recoveries may indicate a possible lag effect that could be related to slow vegetation recovery and possibly still inhospitable sediment conditions. Moreover, the recovery varied with sites that were probably related to the extent of pre-typhoon mangroves. Although the NDVI and LAI values are correlated to post-typhoon recovery, its fluctuations at different sites and at different post-typhoon periods may indicate the role of localized site-specific factors (e.g., mangrove extent and possibly species composition) in post-typhoon recovery.

\section{ACKNOWLEDGEMENT}

We thank Ms. Melanie Q. Germentil for extending financial help for the publication of this research. We also like to thank our friends and families who have given us strength to push through. This would not have been possible without your unwavering love and support. And last but not the least, we acknowledge the JICA-funded Comprehensive Assessment and Conservation of Blue Carbon Ecosystems and their Services in the Coral Triangle (BlueCARES) Project, 5-year cooperation (2017-2022) under the Science and Technology Research Partnership for Sustainable Development (SATREPS) Program supported by Japan International Cooperation Agency (JICA) and Japan Science and Technology Agency (JST). The project aims to conserve the blue carbon ecosystems that can contribute to mitigating the adverse effects of climate change in the context of sustainable development.

\section{REFERENCES}

Akbar, M.R., Arisanto, P.A.A., Sukirno, B.A., Merdeka, P.H., Priadhi, M.M., Zallesa, S., 2020: Mangrove vegetation health index analysis by implementing NDVI (normalized difference vegetation index) classification method on sentinel-2 image data case study: Segara Anakan, Kabupaten Cilacap. International Conference on Fisheries and Marine. IOP Conf. Series: Earth and Environmental Science 584 (2020) 012069.

Alura, D., Alura, R.P., 2016: Regeneration of Mangrove Forest Devastated by Typhoon Haiyan in Eastern Samar, Philippines. International Journal of Current Research. Vol 8, Issue 6, pp. 32373 - 32377.

Alura, D., Alura N., Alura, R.P., 2015: Mangrove Forest and Seagrass Bed of Eastern Samar, Philippines: Extent of Damage by Typhoon Yolanda. International Journal of Novel Research in Life Sciences. Vol.2, Issue 5 pp.30-35.

Baloloy, A., Blanco, A. Sta.Ana, R., Nadoka, K., 2020:. Development and application of a new mangrove vegetation index (MVI) for rapid and accurate mangrove mapping. ISPRS Journal of Photogrammetry and Remote Sensing 166 (2020) 95-117, doi.org/10.1016/i.isprsiprs.2020.06.001

Buitre, M.J., Zhang, H., 2019: The Mangrove Forests Change and Impacts from Tropical Cyclones in the Philippines Using Time Satellite Imagery. Remote Sensing. Vol 11, Issue 668, doi.org/10.3390/rs11060688.

Carlos, C., Delfino, R.J., Juanico, D.E., David, L., 2015: Vegetation resistance and regeneration potential of Rhizophora, Sonneratia and Avicennia in the Typhoon Haiyan-affected mangroves in the Philippines: Implications on rehabilitation practices. Climate Disaster and Development Journal. Vol.1, Issue 1, October 2015, doi.org/ 10.18783/cddj.v001.i01.a01.

EOS.com.,2019: NDVI FAQ: ALL YOU NEED TO KNOW
ABOUT https://eos.com/blog/ndvi-faq-all-you-need-to-know-about-nd vi/

Flores-Cárdenas, F., Millán-Aguilar, O., Díaz-Lara, L., Rodríguez-Arredondo, L., Hurtado-Oliva, M.A., Manzano-Sarabia, M., 2018: Trends in the Normalized Difference Vegetation Index for Mangrove Areas in Northwestern Mexico. Journal of Coastal Research. Vol. 34, No.4 (July 2018), pp. 877-882 (6).

Garcia, K. B., Malabrigo, P. L., \& Gevaña, D. T., 2013: Philippines' Mangrove Ecosystem: Status, Threats and Conservation. Mangrove Ecosystems of Asia, 81-94. doi.org/ 10.1007/978-1-4614-8582-7_5

Giri, C., E. Ochieng, L.L.Tieszen, Z. Zhu, A. Singh, T. Loveland, J. Masek, and N. Duke., 2013: Global Mangrove Forests Distribution, 2000. Palisades, NY: NASA Socioeconomic Data and Applications 
Center (SEDAC).

https://doi.org/10.7927/H4J67DW8.

Giri, C., 2016:. Observation and Monitoring of Mangrove Forests Using Remote Sensing: Opportunities and Challenges. Remote Sensing, 8(9), 783. doi: 10.3390/rs8090783

Gupta, K., Mukhopadhyay, A., Giri, S., Chanda, A., Majumdar, S.D., Samanta, S., Mitra, D., Samal, R.N., Pattnaik, A.K., Hazra, S., 2018: An index for discrimination of mangroves and non-mangroves using LANDSAT 8 OLI imagery. MethodsX. 2018;5:1129-1139; doi:10.1016/j.mex.2018.09.011

Long, J.B. \& Giri C., 2011: Mapping the Philippines' Mangrove Forests Using Landsat Imagery. Sensors 2011, 11(3), 2972-2981; https://doi.org/10.3390/s110302972

Malabrigo, P.L., Umali, A.G., Replan, E., 2016: Damage Assessment and Recovery Monitoring of the Mangrove Forests in Calauit Island Affected by Typhoon Haiyan (Yolanda). University of the Philippines Los Banos: Journal of Environmental Science and Management. Special Issue No.2, pp. 39 -46. ISSN 0119-1144.

Salmo III, S.G., Gianan, E. L., 2019: Post - disturbance carbon stocks and rates of sequestration: Implications on "blue carbon" estimates in Philippine mangroves. Philippine Science Letters, Vol. 12, No. 2, pp. 122-132.

Salmo III, S.G., Lovelock, C.E., Duke, N.C., 2014: Assessment of vegetation and soil conditions in restored mangroves interrupted by severe tropical typhoon 'Chan-hom' in the Philippines. Hydrobiologia (2014) 733:85-102, doi.org/ 10.1007/s10750-013-1766- 4.

Southeast Samar PO Consortium and Guiuan Development Foundation, Inc., 2016: Community-based Biophysical Monitoring of Mangroves in Lawaan, Eastern Samar. In Salmo SG, De La Cruz M and Gianan EL (eds). State of the Mangrove Summit: Central and Eastern Visayas Proceedings. Ateneo de Manila University, 129 pp. 88-100.

Strobl, E., 2019: The Impact of Typhoons on Economic Activity in the Philippines: Evidence from Night Light Intensity. Asian Development Bank (ADB) Economics Working Papers, Series No. 589, doi.org/10.22617/WPS190278-2

Trimble, S. , 2019:. The Importance of Leaf Area Index (LAI) in Environmental and CropResearch. CID Bio-Science, Inc. Retrieved from https://cid-inc.com/blog/theimportance-of-leaf-area-index-in-environmental-and-crop-resea $\underline{\mathrm{rch} /}$

Vergano, D., 2013: 5 Reasons the Philippines Is So Disaster Prone. National Geographic. Retrieved from nationalgeographic.com/news/2013/11/131111-

philippines-dangers-haiyan-yolanda-death-toll-rises/ 